\title{
Feasibility of robotic exoskeleton ambulation in a C4 person with incomplete spinal cord injury: a case report
}

\author{
Robert M. Lester ${ }^{1} \cdot$ Ashraf S. Gorgey $\mathbb{I}^{1,2}$
}

Received: 4 December 2017 / Revised: 29 January 2018 / Accepted: 30 January 2018

(c) International Spinal Cord Society 2018

\begin{abstract}
Introduction To determine whether an individual with $\mathrm{C} 4$ incomplete spinal cord injury (SCI) with limited hand functions can effectively operate a powered exoskeleton (Ekso) to improve parameters of physical activity as determined by swingtime, up-time, walk-time, and total number of steps.

Case presentation A 21-year-old male with incomplete chronic (>1 year postinjury) SCI C4, participated in a clinical exoskeleton program to determine the feasibility of standing up and walking with limited hand functions. The participant was invited to attend 3 sessions including fitting, familiarization and gait training separated by one week intervals. Walktime, up-time and total number of steps were measured during each training session. A complete body composition assessment using dual-energy X-ray absorptiometry (DXA) of the spine, knees and hips was conducted before training.

Using a platform walker and cuffing both hands, the participant managed to stand up and ambulate successfully using exoskeleton. Over the course of 2 weeks, maximum walk-time increased from 7 to 17 min and number of steps increased from 83 to 589 steps. The total up-time increased from 19 to $31 \mathrm{~min}$.

Discussion Exoskeleton training may be a safe and feasible approach for persons with higher levels of SCI after effectively providing a supportive assistive device for weight shifting. The current case study demonstrates the use of a powered exoskeleton for an individual with high level tetraplegia (C4 and above) and limited hand functions.
\end{abstract}

\section{Introduction}

Individuals with tetraplegia account for over $50 \%$ of the entire spinal cord injury (SCI) population and over $20 \%$ have neurological injuries above $\mathrm{C} 4$ [1]. A recent quasiexperimental study was conducted to assess the safety and feasibility of exoskeleton gait-training in 52 individuals recruited from nine European rehabilitation centers [2]. After 8 weeks of exoskeleton training, improvements were noted in gait characteristics and no serious adverse events were observed in all subgroups. However, of the 52 subjects enrolled, no participants had a level of injury above C5. Because the current technology is not approved for those

Ashraf S. Gorgey

ashraf.gorgey@va.gov

1 Spinal Cord Injury and Disorders Service, Hunter Holmes McGuire VA Medical Center, Richmond, VA, USA

2 Department of Physical Medicine and Rehabilitation, Virginia Commonwealth University, Richmond, VA, USA with higher levels of injury, this subsequently results in excluding over $20 \%$ of the SCI population from participating in exoskeleton locomotor training. Exoskeleton gait training may provide health benefits by promoting level of physical activity, improving cardiovascular parameters and quality of life after SCI [3].

Physical impairment and limited mobility often result in survivors restricted to lifelong wheelchair status and at high risk of developing secondary chronic diseases [4-8]. These comorbidities may include psychosomatic, metabolic and cardiovascular health consequences, as well as increased socioeconomic burden after SCI [4-8]. The economic burden for persons with SCI and their families is increasing at an alarming rate, along with decreasing mortality as a result of medical advancement [9]. Previous interventions have attempted to improve locomotion and mobility using longleg braces, hip-knee-ankle foot orthosis, Parastep systems powered by functional electrical stimulation, bodyweightsupported treadmill training and robotic treadmills [10-17]. Locomotor training has been associated with improved upper and lower body motor-strength, functional activities, psychological arousal, bowel sensation and even 
Table 1 Range of motion, upper and lower extremity strength and modified ashworth scores

\begin{tabular}{|c|c|c|}
\hline & Right & Left \\
\hline \multicolumn{3}{|l|}{ Passive range of motion } \\
\hline Shoulder Ext. & $>50^{\circ}$ & $25^{\circ}$ \\
\hline Elbow Ext. & $>40^{\circ}$ & F-ROM \\
\hline Wrist Ext. & F-ROM & F-ROM \\
\hline Hip Flex. & F-ROM & F-ROM \\
\hline Hip Ext. & F-ROM & F-ROM \\
\hline Knee Flex. & F-ROM & F-ROM \\
\hline Knee Ext. & F-ROM & F-ROM \\
\hline Ankle Plantar Flex. & F-ROM & F-ROM \\
\hline Ankle DF w/Knee Ext. & F-ROM & $>20^{\circ}$ \\
\hline Ankle DF w/Knee Flex. & $>5^{\circ}$ & F-ROM \\
\hline \multicolumn{3}{|l|}{ Upper extremity strength } \\
\hline Shoulder Flex. & 3 & 2 \\
\hline Shoulder Ext. & 3 & 2 \\
\hline Elbow Flex. & 3 & 3 \\
\hline Elbow Ext. & 0 & 2 \\
\hline Wrist Ext. & 1 & 1 \\
\hline Gross Grip & 0 & 0 \\
\hline \multicolumn{3}{|l|}{ Lower extremity strength } \\
\hline Hip Flex. & 0 & 0 \\
\hline Hip Ext. & 0 & 0 \\
\hline Hip abduction & 0 & 0 \\
\hline Knee Ext. & 0 & 0 \\
\hline Ankle dorsiflexion & 0 & 0 \\
\hline Ankle plantar flexion & 0 & 0 \\
\hline \multicolumn{3}{|l|}{ Spasticity } \\
\hline Elbow Flex./Ext. & $1+$ & $1+$ \\
\hline Wrist Flex./Ext. & $1+$ & $1+$ \\
\hline Hip Flex./Ext. & $1+$ & $1+$ \\
\hline Hip adductor & $1+$ & $1+$ \\
\hline Knee Flex./Ext. & $1+$ & $1+$ \\
\hline Ankle plantar Flex. & $1+$ & $1+$ \\
\hline Ankle invertor & $1+$ & $1+$ \\
\hline
\end{tabular}

F-ROM functional range of motion

improvements in blood-glucose regulation [18-21]. However, the main pitfall of these rehabilitation interventions is that they often require extensive energy demands and are likely to lead to fatigue for individuals with SCI. This may prevent individuals from meeting the recommended guidelines for improving physical activity.

The Office of Disease Prevention and Health Promotion (U.S. Department of Health and Human Services) recommends at least $150 \mathrm{~min}(2 \mathrm{~h}$ and $30 \mathrm{~min})$ a week of moderate-intensity, or $75 \mathrm{~min}(1 \mathrm{~h}$ and $15 \mathrm{~min})$ a week of vigorous-intensity aerobic activity to reduce cardiometabolic risk factors in the general population [22].
Studies have shown that greater daily leisure-time physical activity is associated with lower risks of chronic disease in adults with SCI [23-26]. Compared to the general population, two-thirds of the SCI population is considered either overweight or obese [27]. Recently released ISCOS guidelines recommended that persons with SCI should engage in at least $20 \mathrm{~min}$ of moderate to vigorous intensity aerobic exercise three times per week to improve cardiorespiratory fitness $[28,29]$.

We have previously demonstrated that robotic exoskeleton training may improve parameters of physical activity in persons with SCI. Over the course of 10 to 15 weeks, participants walked once weekly using a powered exoskeleton (Ekso) for approximately $1 \mathrm{~h}$. The report demonstrated improvements in maximum walking time, total number of steps, energy expenditure and oxygen uptake during exoskeleton training. A modest reduction in fat mass was observed in one participant following training [3]. However, all participants were capable of using assistive devices (walker or Canadian crutches) to initiate weight shifting. Failure to initiate weight shifting may preclude exoskeleton ambulation, which may be the case in persons with impaired hand functions.

The current case report demonstrated the use of powered exoskeleton in a male individual with chronic $(>1$ year postinjury) C4 incomplete SCI with impaired grip strength or inability to functionally extend his elbows. The purpose of the current case report is to document the meticulous screening process, device setup and overall feasibility of exoskeleton training in this unique subset of the SCI population.

\section{Case presentation}

The study was conducted as part of a clinical rehabilitation program. The data was analyzed retrospectively to determine whether an individual with higher level SCI and limited hand functions could effectively operate a powered exoskeleton. The current case report was approved by the local ethical committee at the Hunter Holmes McGuire VA Medical Center. All study procedures were conducted in accordance with the declaration of Helsinki.

An Ekso-GT powered exoskeleton was used to provide locomotion to an individual (male; age: 21 years; height: $1.86 \mathrm{~m}$; weight: $81.6 \mathrm{~kg}$; BMI: $23.7 \mathrm{~kg} / \mathrm{m}^{2}$ ) with chronic $\mathrm{C} 4$ AIS B (i.e. intact sacral sparing) tetraplegia. The classification was determined using the ASIA/ISCoS International Standards for Neurological Classification of Spinal Cord Injury (ISNCSCI). The sensory level was classified at C4 and motor level at $\mathrm{C} 5$ on both the right and left sides. For light touch and pin-prick sensation, normal score was detected up to $\mathrm{C} 4$ (score $=2$ ), altered sensation from C5 to $\mathrm{T} 1$ (score $=1$ ) and absent sensation from T2 to S4-5 (score 
$=0)$. Total light touch sensory scores were 10 and 12 and pin-prick sensation was 10 and 6 out of 56 for right and left sides, respectively. The sacral sparing was determined by examining the perianal sensation (S4-5) and deep anal pressure. The participant was found to have a deep anal pressure and his perianal sensation was scored zero on both sides. A detailed description of the robotic device was previously published elsewhere [30, 31].

Prior to enrollment, written clearance was provided by the participant's medical doctor to ensure the subject was safe to engage in the exoskeleton program. Dual energy $\mathrm{x}$ ray absorptiometry (DXA) scans were conducted to assess bone mineral content (BMC) of total body, knees and hips. Total T-scores less than $2.5 \mathrm{SD}$ or BMD less than $0.6 \mathrm{~g} / \mathrm{cm}^{2}$ at the knee joints would result in elimination from the program. The participant underwent measurements of body weight and height as previously described $[30,31]$. The skin was also checked for any marks or redness prior to enrollment and immediately after each training session to protect against development of pressure sores from exoskeleton training. Moreover, his primary caregiver was instructed to provide any immediate feedback about any changes in his skin coloration.

\section{Familiarization session}

The participant was invited back to the McGuire VA Medical Center to conduct a familiarization session. A patient evaluation was conducted, including an assessment of the participant's grip strength to determine if any additional assistive devices were necessary. The patient's evaluation included upper and lower extremity ROM, strength and spasticity using the Modified Ashworth Scale (Table 1). Based on the assessment and the participants limited grip strength, a platform attachment was added to the Ekso walker and the hands were cuffed to the handles of the walker (Fig. 1). The participant and his companion had the opportunity to ask questions to better understand the benefits of exoskeleton gait-training after SCI.

\section{Fitting}

Body measurements were taken to properly fit the subject in the device, including the following: hip width (distance between two greater trochanters), upper leg length (greater trochanter to the lateral aspect of joint line of the knee joint) and lower leg length (lateral aspect of joint line of the knee joint to the bottom of the foot) were measured to appropriately adjust the width and legs of the robotic suit. Ankle stiffness of the Ekso unit was also adjusted based on completeness of injury and the strength of the anterior tibial muscle groups (lower extremity muscle score $=0$; Table 1 ).

\section{Gait-training sessions}

The participant started his first training session standing and walking in the device. Blood pressure and heart rate were monitored prior to and following each training session, and the participant was instructed to communicate any discomfort during training. The participant was transferred from his power wheelchair and into the robotic device using a mobile ceiling lift. The participant was then properly seated on top of the posterior-sling to facilitate standing, especially with limited arm strength. An assistant held the posterior sling before, during and directly after transfer to ensure appropriate standing and the participant's hips and trunk were properly aligned with the hips embedded all the way in the device, while carefully adjusting the robotic leg to ensure a tight and secure fitting.

A research assistant fit the participant's legs into the device starting with the shoe-supports (distally) and moving towards the trunk (proximally). Each leg strap was fastened securely but not overly-tightened to prevent impairments in circulation or episodes of autonomic dysreflexia or skin irritation. After each leg was secured, the abdominal support was attached to the trunk and shoulder straps fastened. The platform walker (adjusted for participant's height) was then positioned in front of the participant for standing.

The Ekso unit offers a gait training mode with a range of features. For the initial session, we used the "first-step mode" in which steps are manually controlled by the therapist, mainly to allow the participant to focus solely on maintenance of balance and posture and moving the platform walker forward with limited arm strength. An assistant was allowed to walk in front of the participant to control and pace the movement of the walker during exoskeleton ambulation. Before standing, the software was adjusted based on the recommendation from the manufacturer and to ensure a viable walking pattern/speed (Table 2). The length of the session and progression in walking time was based on subject's performance and his willingness to continue. After each training session, the participant's thighs and lower back were checked for possible skin irritation that may result from shear stress during exoskeleton ambulation. As a precaution, a fabric cushion was placed against the sacral area to avoid any skin irritation.

The second gait-training session was conducted using the previous protocol, however, the "pro-step mode" was applied, which allows the stepping pattern of the robotic suit to be determined by the individual's lateral and forward weight shifting. In other words, to initiate a right step the participant must lean left and forward signaling the exoskeleton to right step and vice versa. Blood pressure (BP) and heart rate (HR) were measured before and after walking. Following each training session, swing-time (s), stand- 

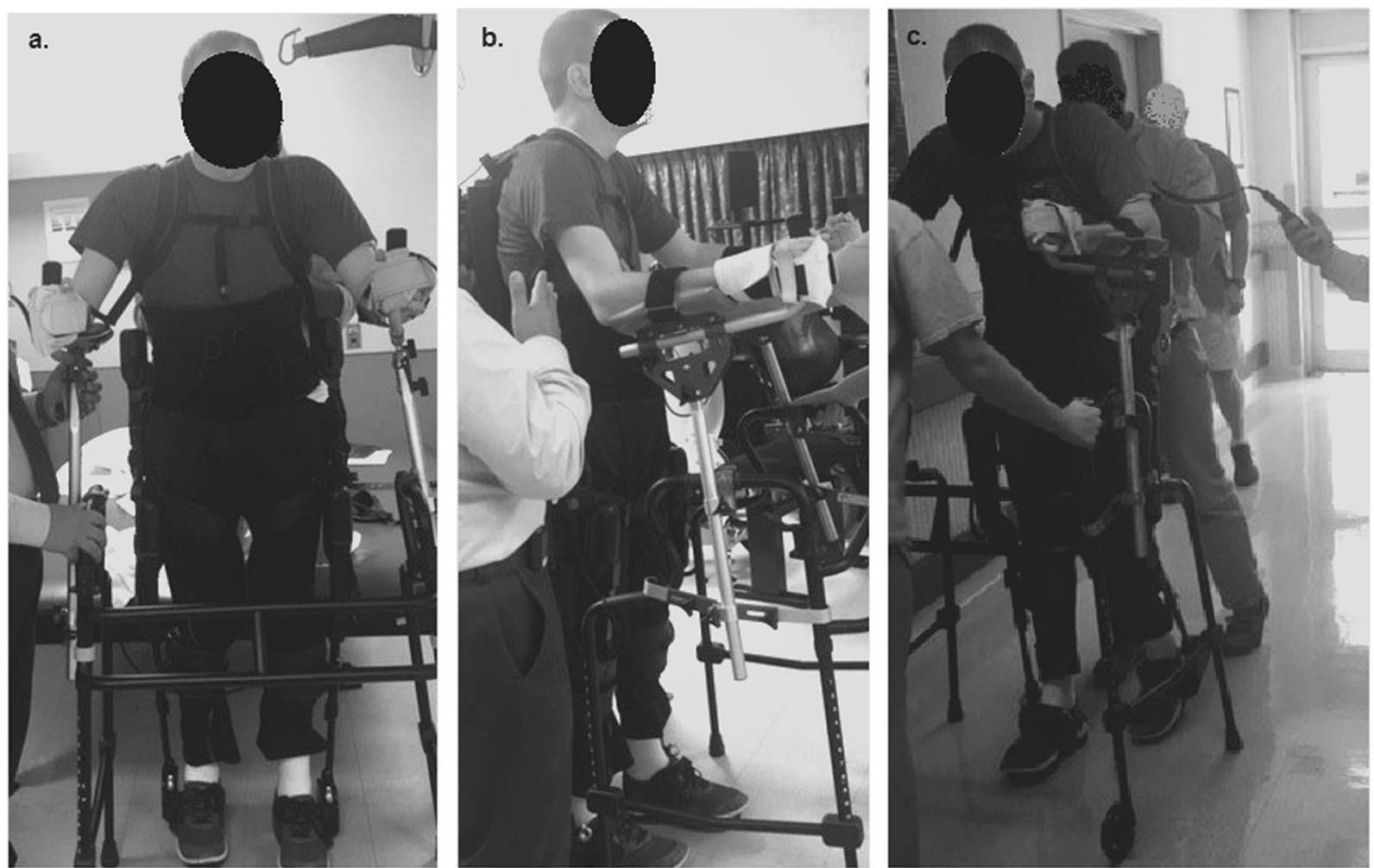

Fig. 1 a Frontal view of subject standing upright in exoskeleton device using rolling platform walker. b Lateral view of device setup, showing hand splints used to cuff the participant's hands to the platform

time (s), walk-time (min), stand up time (min), and number of steps were recorded.

\section{Result}

The subject was a 21-year-old male having a C4 AIS B SCI since 2013 and used a power wheelchair for mobility. During the initial familiarization session, no steps were taken. The participant used a rolling platform walker for each of the two gait-training sessions. During the initial gait-training session using "first step mode" the subject walked a total of 83 steps for a total walk-time of $7 \mathrm{~min}$ and up-time of $19 \mathrm{~min}$. Before starting the first training session, $\mathrm{BP}$ and $\mathrm{HR}$ were $111 / 77 \mathrm{mmHg}$ and $69 \mathrm{bpm}$; after training $\mathrm{BP}$ and HR were $117 / 74 \mathrm{mmHg}$ and $74 \mathrm{bpm}$, respectively. The participant reported minor irritation and redness of the lower back; therefore, a cushion was placed between the sacral region and exoskeleton unit for future sessions. During the following session using "pro step mode", walktime, up-time and number of steps were $17 \mathrm{~min}, 31 \mathrm{~min}$ and 589 steps, respectively. Total up-time and walk-time increased by 12 and $10 \mathrm{~min}$ from the first to final sessions. The subject initiated over 500 more steps during his final session. Swing time and stand time were 1.2 and $3.5 \mathrm{~s}$, attachment of the walker. c Ambulation using exoskeleton. Two assistants are positioned in the back and front of the subject to aid in maintenance of balance and movement of the platform walker.

respectively. $\mathrm{BP}$ and $\mathrm{HR}$ remained within safe range and well-recovered (Pre: $88 / 58 \mathrm{mmHg}$ and $82 \mathrm{bpm}$; Post: 122/ $82 \mathrm{mmHg}$ and $60 \mathrm{bpm}$ ) following the second exoskeleton training session.

\section{Discussion}

The National Spinal Cord Injury Statistical Center (NSCISC) estimates there are approximately 282,000 persons currently living in the United States with SCI with an annual incidence of 17,000 new cases each year. Those with tetraplegia account for over $50 \%$ of persons with SCI [1]. Traumatic SCI often results in either a complete inability or significant limitation in the ability to walk, requiring approximately $70 \%$ of persons with SCI to use a power or manual wheelchair as their primary mode of mobility [32]. This greatly reduces the ability and likelihood of engaging in physical activity, which is an independent risk factor for several cardio-metabolic conditions including carbohydrate intolerance [33, 34], insulin resistance [35, 36], lipid abnormalities [37, 38], and cardiovascular disease [39]. In fact, prolonged sitting time is an independent cardiovascular risk factor and associated with heightened mortality [40]. 
Table 2 Software settings during the course of the exoskeleton training program

\begin{tabular}{lllllll}
\hline $\begin{array}{l}\text { Step length } \\
(\mathrm{cm})\end{array}$ & $\begin{array}{l}\text { Step height } \\
(\mathrm{cm})\end{array}$ & $\begin{array}{l}\text { Swing time } \\
(\text { seconds })\end{array}$ & $\begin{array}{l}\text { Stand time } \\
(\text { seconds })\end{array}$ & $\begin{array}{l}\text { Knee flexion } \\
\text { angle (degrees) }\end{array}$ & $\begin{array}{l}\text { Hip flexion } \\
\text { angles (degrees) }\end{array}$ \\
\hline 12.5 & 0.8 & 1.2 & 3.5 & 0 & 0 & Assistance \\
\hline
\end{tabular}

Tetraplegic individuals with higher levels of injuries (C1C7) have been shown to have lower lean mass, greater fat mass and reduced bone mineral content in the upper and lower extremities, as compared to persons with paraplegia $[41,42]$. These differences in body composition highlight the need for specific exercise interventions designed to increase the level of physical activity in persons with higher levels of SCI. The current case report provides initial evidence that persons with higher levels of cervical SCI may safely operate powered exoskeletons with the assistance of trained staff and additional support mechanisms (i.e. platform walker and hand straps).

The participant walked 83 and 589 steps during the first and second gait-training sessions. Though this is a fraction of the daily recommended 10,000 steps suggested to prevent cardiovascular disease [43], the primary focus of this report was to safely fit the participant in the device, accommodate his limited grip strength and train the subject on how to shift his weight effectively to initiate stepping and maintain balance in the upright posture. Exoskeleton gait training once weekly for 15 weeks resulted in increasing the number of steps from 59 to 2284 in subjects with complete and incomplete-SCI (C5-T4) [3]. It is unrealistic for persons with motor complete SCI (i.e. AIS A or B) to attain the recommended steps per day without increasing the speed of exoskeleton ambulation. The gait speed must be adjusted according to the subjects' performance and ability to weight shift while maintaining balance. Ensuring postural balance is of paramount importance when training individuals with higher level of injuries because of limited trunk control [44]. Considering a swing-time of $1.2 \mathrm{~s}$ $(\sim 0.19 \mathrm{~m} / \mathrm{sec})$, a person may need to walk approximately $5 \mathrm{~h}$ per day to meet the recommended guidelines. This may be unlikely for those with higher level injuries, newly injured or those with limited cardiovascular capacity. Therefore, the number of steps may not be an effective measure of treatment when using exoskeleton devices; instead, oxygen uptake, energy expenditure and/or body composition assessments may provide future insights on the effectiveness exoskeleton training to combat cardiometabolic diseases after SCI.

Studies have shown improvements on spasticity, level of physical activity, bowel management and quality of life after SCI; [3, 45-48] however, it is still unclear whether this emerging technology offers any benefits beyond the existing standard of care, such as a wheelchair or standing frame.
Certain aspects of exoskeletons may need to be improved to ensure more individuals can be qualified for training. Of the major brands available in the U.S., the weight of devices ranges from 26-66 lbs. which may be difficulty for some individuals with SCI to carry or lift for transportation compared to lighter wheelchairs [47-49]. Future designs should focus on implementing highly durable materials that provide less weight and allow faster speed without compromising balance.

Our findings suggest that persons with higher level cervical injuries and limited hand functions may have the potential to operate an exoskeleton, previously considered only for those with C6 and below. Studies using this technology have opted to exclude those with higher level injuries above C5, excluding over $20 \%$ of the SCI population from participating in exoskeleton locomotor training. This is likely due to the perceived risks of injury to the participant; however, we believe screening criteria (i.e. bone mineral content, ROM and medical history) should serve as an indicator of eligibility in training programs, independent of the level of injury. Future studies may benefit by being more inclusive to persons with higher level of injuries, given that the necessary trained staff and assistive devices are available.

\section{Conclusion}

Exoskeleton training may be a safe and feasible approach for persons with higher levels of SCI after effectively providing supportive assistive device to allow appropriate weight shifting. The current case study demonstrates feasibility of limited use of a powered exoskeleton in an individual with high tetraplegia (C4) and limited hand functions. Studying the effects of training on individuals with higher level injuries will provide future insights on the full applicability of this technology in persons with tetraplegia.

Acknowledgements We would like to thank the participant who devoted the time and effort to participate in the case study. We would like to thank Hunter Holmes McGuire Research Institute and Spinal Cord Injury Services and Disorders for providing the environment to conduct clinical human research trials. Ashraf Gorgey is currently supported by the Department of Veteran Affairs, Veteran Health Administration, Rehabilitation Research and Development Service (B7867-W) and DoD-CDRMP (W81XWH-14-SCIRP-CTA). 


\section{Compliance with ethical standards}

Conflict of interest The authors declare that they have no conflict of interest.

\section{References}

1. National Spinal Cord Injury Statistical Center. Complete public version of the 2016 Annual Statistics Report for the Spinal Cord Injury Model Systems. https://www.nscisc.uab.edu/Public/2016\% 20Annual\%20Report\%20-\%20Complete\%20Public\%20Version. pdf, Accessed 23 Jan 2018

2. Baunsgaard CB, Nissen UV, Brust AK, Frotzler A, Ribeill C, Kalke YB. et al. Gait training after spinal cord injury: safet, feasibility and gait function following 8 weeks of training with the exoskeletons from Ekso Bionics. Spinal Cord. 2018;56:106. In Press.

3. Gorgey AS, Wade R, Sumrell R, Villadelgado L, Khalil RE, Lavis T. Exoskeleton training may improve level of physical activity after spinal cord injury: a case series. Top Spinal Cord Inj Rehabil. 2017;23:245-55.

4. Kocina P. Body composition of spinal cord injury adults. Sports Med. 1997;23:48-60.

5. Bauman WA, Spungen AM. Carbohydrate and lipid metabolism in chronic spinal cord injury. J Spinal Cord Med. 2001;24:266-77.

6. Bauman WA, Spungen AM. Coronary heart disease in individuals with spinal cord injury: assessment of risk factors. Spinal Cord. 2008;46:466-76.

7. Dolbow DR, Gorgey AS, Daniels JA, Adler RA, Moore JR, Gater DR Jr. The effects of spinal cord injury and exercise on bone mass: a literature review. Spinal Cord. 2012;50:170-1.

8. Gorgey AS, Dolbow DR, Dolbow JD, Khalil RK, Castillo C, Gater DR. Effects of spinal cord injury on body composition and metabolic profile-part I. J Spinal Cord Med. 2014;37:693-702.

9. Strauss D, DeVivo M, Shavelle R, Brooks J, Paculdo D. Economic factors and longevity in spinal cord injury: a reappraisal. Arch Phys Med Rehabil. 2008;89:572-4.

10. Dobkin B, Apple D, Barbeau H, Basso M, Behrman A, Deforge $\mathrm{D}$, et al. Weight-supported treadmill vs over-ground training for walking after acute incomplete SCI. Neurology. 2006;66:484-93.

11. Giangregorio LM, Hicks AL, Webber CE, Phillips SM, Craven BC, Bugaresti JM, et al. Body weight supported treadmill training in acute spinal cord injury: impact on muscle and bone. Spinal Cord. 2005;43:649-57.

12. Hornby TG, Zemon DH, Campbell D. Robotic-assisted, bodyweight-supported treadmill training in individuals following motor incomplete spinal cord injury. Phys Ther. 2005;85:52-66.

13. Maxwell JL, Granat MH, Baardman G, Hermens HJ. Demand for and use of functional electrical stimulation systems and conventional orthoses in the spinal lesioned community of the UK. Artif Organs. 1999;23:410-2.

14. Ambrosia RD, Solomonow M, Baratta R. Current status of walking orthosis for thoracic paraplegics. Iowa Orthop J. 1995;15:174-81.

15. Gorgey AS, Poarch H, Miller J, Castillo T, Gater DR. Locomotor and resistance training restore walking in an elderly person with a chronic incomplete spinal cord injury. NeuroRehabilitation. 2010;26:127-33.

16. Gorgey AS, Poarch H, Harnish C, Miller JM, Dolbow D, Gater DR. Acute effects of locomotor training on neuromuscular and metabolic profile after incomplete spinal cord injury. NeuroRehabilitation. 2011;29:79-83.

17. Fineberg DB, Asselin P, Harel NY, Agranova-Breyter I, Kornfeld $\mathrm{SD}$, Bauman WA, et al. Vertical ground reaction force-based analysis of powered exoskeleton-assisted walking in persons with motor-complete paraplegia. J Spinal Cord Med. 2013;36:313-21.

18. Morrison SA, Lorenz D, Eskay CP, Forrest GF, Basso DM. Longitudinal recovery and reduced costs after 120 sessions of locomotor training for motor incomplete spinal cord injury. Arch Phys Med Rehabil. 2017;S0003-9993:31285-6.

19. Chilibeck PD, Guertin PA. Locomotor training and factors associated with blood glucose regulation after spinal cord injury. Curr Pharm Des. 2017;23:1834-44.

20. Lam T, Pauhl K, Ferguson A, Malik R, Krassioukov A, Eng JJ. Training with robot-applied resistance in people with motorincomplete spinal cord injury: Pilot study. J Rehabil Res Dev. 2015;52:113-29.

21. Aach M, Cruciger O, Sczesny-Kaiser M, Höffken O, Meindl RCh, Tegenthoff M, et al. Voluntary driven exoskeleton as a new tool for rehabilitation in chronic spinal cord injury: a pilot study. Spine J. 2014;14:2847-53.

22. Office of Disease Prevention and Health Promotion (http://odphpinfo@hhs.gov). Office of the Assistant Secretary for Health, Office of the Secretary, U.S. Department of Health and Human Services; 2017.

23. Buchholz AC, McGillivray CF, Pencharz PB. Physical activity levels are low in free-living adults with chronic paraplegia. Obes Res. 2003;11:563-70.

24. Buchholz AC, Martin Ginis KA, Bray SR, Craven BC, Hicks AL, Hayes $\mathrm{KC}$, et al. Greater daily leisure time physical activity is associated with lower chronic disease risk in adults with spinal cord injury. Appl Physiol Nutr Metab. 2009;34:640-7.

25. Hicks AL, Martin Ginis KA, Pelletier CA, Ditor DS, Foulon B, Wolfe DL. The effects of exercise training on physical capacity, strength, body composition and functional performance among adults with spinal cord injury: a systematic review. Spinal Cord. 2011;49:1103-27.

26. Hetz SP, Latimer AE, Buchholz AC, Martin Ginis KA, SHAPESCI Research Group. Increased participation in activities of daily living is associated with lower cholesterol levels in people with spinal cord injury. Arch Phys Med Rehabil. 2009;90:1755-9.

27. Gorgey AS, Gater DR Jr. Prevalence of obesity after spinal cord injury. Top Spinal Cord Inj Rehabil. 2007;12:1-7.

28. Martin Ginis KA, van der Scheer JW, Latimer-Cheung AE, Barrow A, Bourne C, Carruthers $\mathrm{P}$, et al. Evidence-based scientific exercise guidelines for adults with spinal cord injury: an update and a new guideline. Spinal Cord. 2018;56:308-21.

29. Fisher JA, McNelis MA, Gorgey AS, Dolbow DR, Goetz LL. Does upper extremity training influence body composition after spinal cord injury? Aging Dis. 2015;6:271-81.

30. Strausser KA, Kazerooni H. The development and testing of a human machine interface for a mobile medical exoskeleton. IEEE/ RSJ International Conference on Intelligent Robots and Systems (IROS). IEEE. 2011;4911e6.

31. Strausser KA, Swift TA, Zoss AB, Kazerooni H, Bennett BC. Mobile exoskeleton for spinal cord injury: development and testing. Arlington: ASME; 2011. 419e25.

32. Dryden DM, Saunders LD, Jacobs P, Schopflocher DP, Rowe BH, May LA, et al. Direct health care costs after traumatic spinal cord injury. Trauma. 2005;59:464-7.

33. Gorgey AS, Caudill C, Sistrun S, Khalil RE, Gill R, Castillo T, et al. Frequency of dietary recalls, nutritional assessment, and body composition assessment in men with chronic spinal cord injury. Arch Phys Med Rehabil. 2015;96:1646-53.

34. Gorgey AS, Gater DR. Regional and relative adiposity patterns in relation to carbohydrate and lipid metabolism in men with spinal cord injury. Appl Physiol Nutr Metab. 2011;36:107-14.

35. Bauman WA, Spungen AM. Disorders of carbohydrate and lipid metabolism in veterans with paraplegia or quadriplegia: a model of premature aging. Metabolism. 1994;43:749-56. 
36. Karlsson AK. Insulin resistance and sympathetic function in high spinal cord injury. Spinal Cord. 1999;37:494-500.

37. Bauman WA, Spungen AM, Zhong YG, Rothstein JL, Petry C, Gordon SK. Depressed serum high density lipoprotein cholesterol levels in veterans with spinal cord injury. Paraplegia. 1992;30:697-703.

38. Brenes G, Dearwater S, Shapera R, LaPorte RE, Collins E. High density lipoprotein cholesterol concentrations in physically active and sedentary spinal cord injured patients. Arch Phys Med Rehabil. 1986;67:445-50.

39. Bauman WA, Raza M, Spungen AM, Machac J. Cardiac stress testing with thallium-201 imaging reveals silent ischemia in individuals with paraplegia. Arch Phys Med Rehabil. 1994;75:946-50.

40. Rezende LF, Sá TH, Mielke GI, Viscondi JY, Rey-López JP, Garcia LM. All-Cause Mortality Attributable to Sitting Time: Analysis of 54 Countries Worldwide. Am J Prev Med. 2016;51:253.

41. Roop Singh RajeshK, Rohilla Gaurav. Saini, Kiranpreet Kaur. Longitudinal study of body composition in spinal cord injury patients. Indian J Orthop. 2014;48:168-77.

42. Spungen AM, Adkins RH, Stewart CA, Wang J, Pierson RN Jr, Waters RL, et al. Factors influencing body composition in persons with spinal cord injury: a cross-sectional study. J Appl Physiol. 2003;95:2398-407.

43. Haskell WL, Lee IM, Pate RR, Powell KE, Blair SN, Franklin $\mathrm{BA}$, et al. Physical activity and public health: updated recommendation for adults from the American College of Sports Medicine and the American Heart Association. Med Sci Sports Exerc. 2007;39:1423-34.

44. Sinderby C, Ingvarsson P, Sullivan L, Wickstrom I, Lindstrom L. The role of the diaphragm in trunk extension in tetraplegia. Paraplegia. 1992;30:389-95.

45. Miller LE, Zimmermann AK, Herbert WG. Clinical effectiveness and safety of powered exoskeleton-assisted walking in patients with spinal cord injury: systematic review with meta-analysis. Med Devices. 2016;9:455-66.

46. Kressler J, Thomas CK, Field-Fote EC, Sanchez J, WiderströmNoga E, Cilien DC. Understanding therapeutic benefits of overground bionic ambulation: exploratory case series in persons with chronic, complete spinal cord injury. Arch Phys Med Rehabil. 2014;95:1878-87.

47. Asselin P, Knezevic S, Kornfeld S, Cirnigliaro C, AgranovaBreyter I, Bauman WA, et al. Heart rate and oxygen demand of powered exoskeleton-assisted walking in persons with paraplegia. J Rehabil Res Dev. 2015;52:147-58.

48. Evans N, Hartigan C, Kandilakis C, Pharo E, Clesson I. Acute cardiorespiratory and metabolic responses during exoskeletonassisted walking overground among persons with chronic spinal cord injury. Top Spinal Cord Inj Rehabil. 2015;21:122-32.

49. Kozlowski AJ, Bryce TN, Dijkers MP. Time and effort required by persons with spinal cord injury to learn to use a powered exoskeleton for assisted walking. Top Spinal Cord Inj Rehabil. 2015;21:110-21. 